\title{
Sports-Related Concussion in School-Age Children
}

\author{
David S. Younger ${ }^{1,2}$ \\ ${ }^{1}$ Department of Neurology, School of Medicine, The College of Global Public Health, New York University, New York, USA \\ ${ }^{2}$ Health Policy and Management Doctoral Program, School of Public Health, City University of New York, New York, USA \\ Email: youngd01@nyu.edu
}

How to cite this paper: Younger, D.S. (2018) Sports-Related Concussion in SchoolAge Children. World Journal of Neuroscience, 8, 10-31.

https://doi.org/10.4236/wjns.2018.81002

Received: November 28, 2017

Accepted: December 12, 2017

Published: December 15, 2017

Copyright (C 2018 by author and Scientific Research Publishing Inc. This work is licensed under the Creative Commons Attribution International License (CC BY 4.0).

http://creativecommons.org/licenses/by/4.0/

\begin{abstract}
Viewed through the lens of public health, sports-related concussion or mild traumatic brain injury is an epidemic health problem. This paper commences with a scoping review of sport-related concussion and mild traumatic brain injury considering its historical background, clinical definitions, epidemiology, and pathophysiology and treatment. The second section assesses the complex interplay of intrapersonal and interpersonal, community, and societal factors that influence sport-related concussion and mild traumatic brain injury. The third section concludes with recommendations for policy changes and further research to mitigate the health impact of sports-related concussion in adolescent school-age children. The optimal management of sports-related concussion requires care going beyond the acute injury, and into the school setting to maximize their academic and social outcomes. This is more likely to occur when healthcare and educational systems are optimally coordinated.
\end{abstract}

\section{Keywords}

Traumatic Brain Injury, Children, Schools

\section{Introduction}

In the past decade, few subjects have generated as much public interest as concussive brain injury or concussion. News reports on the long-term effects of concussions and chronic traumatic encephalopathy or CTE [1] [2] [3], in football have created a new level of awareness about the seriousness of sports-related concussion (SRC) in the United States (US). National and local organizations representing youth, collegiate and professional sports, as well as health care professionals, have taken significant measures to address this once overlooked issue. Despite its growing health awareness among educators, coaches, physicians, 
psychologists, and parents [4], there is still no unified policy to screen children entering school with a concussion even through such students are at risk for poorer grades, recurrent concussion, alcohol and drug abuse [5]. Addressing the public health aspects of SRC at the level of schools has been a test of our nation's resolve to ameliorate the health impact of adolescent concussion.

The first section of this paper is a scoping review and examination of the historical background, clinical definitions, epidemiology, pathophysiology and treatment of concussion/mild traumatic brain injury (mTBI). The second section assesses the complex interplay of intrapersonal and interpersonal, community, and societal factors that influence SRC employing a social-ecological framework (SEF) model to better understand potential prevention and health mitigation strategies. The third section concludes with recommendations for policy changes and further research.

\section{Section 1. The Scope of Concussion}

\subsection{Historical Background}

In the late 1970s and early 1980s, the Vietnam War provided the impetus for the management of soldiers with TBI and the impetus to initiate trauma centers at major medical centers. Moreover, medical centers graded by their level of preparedness to handle major trauma on a 24-hour basis led to the concept of the "golden hour" of emergency care [6]. During this time, trauma management became more sophisticated, and the Glasgow Coma Scale (GCS) [7] was adopted across the US to classify the severity of TBI. This scale 15-point scare included a classification for minor head injuries that fell between 13 and 15. However, at the time, these milder concussions were viewed as insignificant and such patients discharged after an hour of observation were typically not followed-up further. The National Institutes of Health launched a 3-year multicenter pilot study of more than 1000 moderate and severe TBI patients' data from five major university hospitals into the Trauma Coma Data Bank [8], focusing on immediate neurological impact, and the cognitive and emotional residua caused by TBI. Despite the fact that $80 \%$ of all TBIs were mild, and with few exceptions, the physical and psychological sequela [9] [10] went unnoticed. The 1980s led to compelling evidence for diffuse axonal injury (DAI) as the histopathologic basis of mTBI in experimental animals [11] and affected human subjects who expired due to other causes [12]. The histopathologic basis of mTBI was relevant because traditional brain computed tomography (CT) imaging lacked the sensitivity to identify DAI.

During the 1990s, the assessment of concussion was fueled by research that delved directly into mTBI. Tellier and colleagues [13] cited mounting evidence of the sequela of concussive head injury in adolescents and adults [9]. Up to 20\% of affected patients obtained a perfect (15/15) GCS, but later developed surgically significant acute traumatic intracranial hematoma [14]. Tellier and colleagues [13] noted that adolescents and adults with concussive head injury did not constitute a homogeneous pool. In a retrospective study of 80 cases identified from a 
trauma registry, brain CT demonstrated evidence of intracranial abnormalities in two-thirds of cases with GCSs of 13 to 15 , including $27 \%$ and $45 \%$ of those with scores of 14 and 15.

Even though brain CT underestimated the number of intracranial abnormalities, it was the test of choice for concussion in the first 24 to 48 hours after injury, especially in pediatric patients [15] for several reasons including, its ready availability in emergency departments (ED), ease of performance, lower cost, and superior modality in detecting skull fractures. Newly available magnetic resonance imaging (MRI) modalities such as gradient echo and perfusion and diffusion tensor imaging [16], with its superior ability to detect cerebral contusions, petechial hemorrhages, and white matter injuries, was generally employed 48 hours or more after minor head injury [17] owing instead to its higher cost and limited availability.

In a trend that continued into the 2000s, two schools emerged, clinicians who attributed post-concussive symptoms to microscopic brain damage versus psychological factors motivated in part by malingering. The diagnosis of it was problematic since the majority of patients were diagnosed hours, days, or even months after the injury and had frequent gaps in memory for loss of consciousness (LOC), the hallmark of the earlier mTBI.

In the past decade, research has removed the uncertainty that adolescent concussion due a variety of causes, including SRC, differs substantially from mTBI. DeMatteo and colleagues [18] examined the clinical correlates of the diagnosis of concussion among 434 children with mTBI and SRC to identify the factors that led to the use of this term in a regional pediatric center. Proportional hazards results demonstrated that the concussion label was significantly more likely to be applied to children with GCS scores of 13 to $15(P=0.03)$, and was strongly predictive of an earlier hospital discharge (odds ratio [OR]: 1.5; 95\% confidence interval $[\mathrm{CI}]: 1.2-1.9 ; P=0.003)$; and earlier return to school (OR: 2.4 [95\% CI: 1.6 - 3.7]; $P<0.001)$. The predictive value of the concussion label depended mainly upon the clinical reasoning and decision-making processes of those who evaluated childhood head injuries. While a normal brain CT result likely implied to parents that their child had not sustained an mTBI, this was generally not the intention of physicians who diagnosed a SRC.

There is comparatively less known about the epidemiology and correlates of SRC in adolescents than in adults. According to the National Electronic Injury Surveillance System-All Injury Program [19], from 2001 to 2009, activities associated with the greatest estimated number of mTBI-related ED visits included, bicycling, football, playground activities, basketball and soccer among persons older than 19 years, all which could be group under the label of SRC. The reported prevalence of a single diagnosed SRC in US high school students age 12 to 18 years in 2016 of $19.5 \%$ [20] is similar to regional US surveys [21], and far exceeds the 5\% estimate of mTBI visits among adolescents to US EDs by the Centers for Disease Control and Prevention (CDC) [22]. This discrepancy suggests the need for un- 
iformity in the reporting of concussion and mTBI in adolescents.

\subsection{Definitions}

The term SRC and mTBI are interchangeable. Dematteo and colleagues [18] pointed out the common misunderstanding among professionals and the lay public [23] that an injury described as a concussion, is far less severe than one described as a mTBI. While not all blows or jolts to the head result in a concussion, those that do, are typically associated with a brief change in mental status or LOC. The immediate and short-term symptoms associated with concussion reflect a primary functional cerebral disturbance rather than structural damage. Secondary physical, neurocognitive and neuropsychological symptoms occur in up to a third of cases and persist for up to several months after primary injury, tapering to about $2.5 \%$ at one year [24]. Pervasive symptoms of concussion lead to a disturbance in adaptive independent functioning and the safe performance of activities in school and at home.

There have been several widely used classification of mTBI, each with an application to adolescent SRC. The American Congress of Rehabilitation Medicine (ACRM) [25] first proposed criteria for $\mathrm{mTBI}$ as an alteration of brain function caused by external forces with LOC for 0 to 30 minutes, post-traumatic amnesia (PTA) for less than 24 hours, transient focal neurological deficits, or alteration of mental status. The authors of the ACRM definition deserve credit for moving beyond the previously held notion that mTBI could be diagnosed only if the patient sustained a definite LOC. Prior to this definition, most neurologists diagnosed a concussion only when LOC or PTA were present.

A Summary Statement of the Quality Standards Subcommittee of the American Academy of Neurology (AAN) [26] divided concussion into the arbitrary grades of 1 to 3 , based on the severity of concussion as determined by the duration of transient LOC, confusion, or other mental status changes. The criteria of the CDC [27] were less specific requiring any period of observed or self-reported confusion, disorientation, or impaired consciousness with memory dysfunction and LOC at the time of the incident. The World Health Organization (WHO) [28] proposed criteria for mTBI, specifying a GCS score of 13 to 15 at time of presentation to a healthcare professional indicating minor brain injury. In the same year, the Tenth edition of the International Classification of Diseases [29] enumerated criteria for the diagnosis of post-concussion syndrome (PCS) requiring three of eight symptoms after head trauma: headache, dizziness, fatigue, irritability, difficulty concentrating, memory impairment, insomnia, and intolerance to stress, emotion, or alcohol. Yet the diagnosis of concussion remained ill-defined other than emerging 3 months following a concussion, with no specific criteria for the latter other than a 5-minute LOC. The US Department of Veterans Affairs [30] issued clinical guidelines for concussion and mTBI, specifying alteration of consciousness of less than 24 hours and normal structural neuroimaging. New conclusive evidence-based guidelines for the evaluation and management of SRC by the AAN [31], updating 
the 1993 Practice Parameter [26], differ in the inclusion of factors that mitigate concussion risk, diagnostic tools to identify SRC and post-concussive symptoms. Patients with $\mathrm{mTBI}$ who have positive findings on neuroimaging such as subarachnoid hemorrhage and small contusions are termed "complicated" [32]; however, there is yet a consensus as to whether a complicated mTBI constitutes a distinct subgroup [33].

\subsection{Epidemiology}

A six-year study by Blue Cross Blue Shield [34] analyzed database claims for concussion from 2010 to 2015, noting a $71 \%$ increase in concussion rates from 8.9 to 15.2 diagnoses per 1000 members in children aged 10 through 19 years, compared to a $26 \%$ increase, from 1.9 to 2.4 diagnoses per 1000 in adults aged 20 to 64 years. The increases occurred from 2010 to 2013 when most states enacted concussion legislation mandating reporting. Children age 10 to 19 years were five-times more likely to be diagnosed with a concussion than all other age groups combined, with the most dramatic spike in its incidence occurring in the fall, when the most popular school-based and extramural contact sports such as football, soccer and lacrosse are in season. Boys had an overall concussion rate of 7.0 per 1000 that increased $48 \%$ from 11.5 to 17.0 per 1000 , compared to girls who had an overall concussion rate of 3.7 per 1000, increasing $118 \%$ from 6.1 to 13.3 per 1000 members, during the study period. The national average of the rate of concussion diagnoses increased nearly two-fold in all states between 2010 and 2015, especially in those age 10 to 19 , from 8.9 per 1000 members to 15.2 per 1000 members, with the highest rates (nearly three-fold) in the Northeast.

Among head coaches and 3063 players from 103 secondary school football teams in Minnesota who responded to mailed questionnaires about injury incidence and concomitant health care provision [35], the total injury rate was 78 injuries/100 players, and SRCs in 19/100 players. Overall, 69\% of players who experienced LOC returned to play the same day. Symptoms of concussion lasted up to nine months following the end of the season, with six cases reporting permanent disabilities. Players with a prior history of LOC had a four-fold increased risk of another SRC.

Mild TBI comprised 5.5\% of 23,566 injuries among 264 certified athletic trainers in 235 schools who recorded injury and exposure data for high school varsity athletes participating in boys' and girls' high school teams 1995 to 1997 [36]. Football accounted for two-thirds of the cases, while wrestling, soccer, basketball, softball, baseball, field hockey, and volleyball accounted for the remaining cases in order of declining frequency.

The occurrence of neurological injury in sports is not a new phenomenon. As one study demonstrated [37], the majority of SRCs occur without LOC. Since 1990, the CDC has been developing a multistate mTBI surveillance system [38] using standardized methods to collect information. As expected, rates were highest in children, adolescents, and young adults respectively, with an incidence of 10 and 7.5 per 100,000 at age 15 to 24 and 5 to 14 years, compared to 3.8 and 
2.4 per 100,000 respectively at age 25 to 34 years, and 35 to 44 years, with progressive decreases in later decades.

A 2015 report of The National Electronic Injury Surveillance System-All Injury Program (NEISS-AIP) [39] cited 3.42 million ED visits for SRCs from 2001 to 2012. During this period, the rates of SRC treated in US EDs significantly increased in both boys and girls regardless of age (all $P S<0.001$ ). For boys, significant increases ranged from a low of $45.8 \%$ (ages 5 - 9) to a high of $139.8 \%$ (ages 10 - 14), and for girls, from $25.1 \%$ (ages 0 - 4) to $211.5 \%$ (ages 15 - 19) (all $P s<0.001$ ). Every year, boys have about twice the rate of SRCs than girls. Approximately $70 \%$ of all SRCs occurs in persons aged 0 to 19 years with the largest number due to bicycling, football, and basketball injuries. Among girls, the largest number of SRCs occurs during bicycling, playground activities, and horseback riding. Approximately $89 \%$ of boys and $91 \%$ of girls with an SRC were treated and released from EDs. These data underestimate the full impact of SRC as many mild sports injuries in school are undiagnosed, and not all those experiencing it seek treatment.

An estimated 20.3\% (95\% CI: 17.7 - 23.2) of 6,383 Ontario middle and high school students enrolled in grades 7 through 12 (age range: 13 - 20 years), acknowledged a lifetime TBI event in 2015 [40]. A larger survey cohort of 8,915 Ontario high school students [5] showed a lifetime prevalence of mTBI in $20.2 \%$ (95\% CI, 18.1\% - 22.4\%), with 5.6\% (95\% CI, 4.2\% - 7.5\%) of students reporting at least one mTBI in the preceding twelve months, and $14.6 \%$ (95\% CI, $13.4 \%$ $15.9 \%)$ reporting $\mathrm{mTBI}$ in their lifetime. Sports injuries accounted for more than one-half of the cases of mTBI, with a lifetime OR of 3.93 (95\% CI, $2.12-7.27$ ) among high school students who reported poor school grades. Those who reported occasional to frequent consumption of alcohol and frequent use of cannabis in the preceding twelve months, respectively had ORs of 2.03 (95\% CI 1.33 - 3.09) and 1.69 (95\% CI 1.12 - 2.55) compared to those who abstained.

Data from the High School Reporting Information Online [41] were analyzed to calculate rates, describe patterns, and evaluate potential risk factors noting that SRCs represented 8.9\% $(n=396)$ of all high school athletic injuries. The rates of SRCs were highest in the sports of football and soccer. According to a clinical report from the Council on Sports Medicine and Fitness of the American Academy of Pediatrics [15], data are significantly lacking about SRCs in grade school and middle school athletics, which highlights the need for more research in this younger age group.

The literature, which indicates a wide range in incidence of PCS following SRC, varying from $1.5 \%$ to $15 \%$ [42] [43] [44] [45], has been problematic due to several factors including, variations in the populations studied, the period used for making the diagnosis, and measurable risk factors. Morgan and colleagues [46] analyzed candidate variables for the development of PCS among 40 young athletes following SRCs, noting significance for a preinjury mood disorder (OR $17.9,95 \%$ CI $2.9-113.0, p=0.002$ ), family history of mood disorders (OR 3.1, 95\% CI $1.1-8.5, p=0.026$ ), and delayed symptom-onset (OR 20.7, 95\% CI 3.2 132.0, $p<0.001)$. The higher prevalence of mood disorders and psychiatric ill- 
ness were consistent with previous findings that preinjury parental anxiety and family and life stressors predicted protracted PCS in children [47] [48].

O'Connor and colleagues [49] described the epidemiology of SRC in 27 sports among 147 high schools during the 2011 to 2012 and 2013 to 2014 academic years, in the National Athletic Treatment, Injury and Outcomes Network (NATION). The overall SRC rate was 3.89 per 10,000 athletic events (AE) among 2004 SRC in all sports. Football had the highest overall SRC rate (9.21/10,000 AEs), followed by boys' lacrosse (6.65/10,000 AEs) and girls' soccer (6.11/10,000 AE). No SRCs were reported in boys' crew, cross-country, golf, and swimming and diving and girls' golf. During competitions, football (19.87/10,000 AEs), boys' lacrosse (17.51/10,000 AEs), and girls' soccer (17.16/10,000 AEs) had the highest SRC rates. During practice sessions, football (6.78/10,000 AE), boys' wrestling (4.75/10,000 AEs), and girls' lacrosse (3.44/10,000 AEs) had the highest SRC rates. Overall, the SRC rate was higher in competition than in practice (risk ratio (RR) 3.30; 95\% CI $3.02,3.60)$. Player-to-player contact was the most common mechanism of SRC $(62.8 \%)$ in the following sports: football (79.6\%), boys' soccer (69.9\%), boys' lacrosse (60.4\%), boys' basketball (59.8\%), girls' basketball (53.9\%), and boys' wresting (51.1\%). Player-to-player contact also accounted for a larger proportion of SRCs in boys than in girls (59.1\% versus $39.8 \%$ ) without significant differences in the distributions of mechanism of injury between competitions and practices. More than $50 \%$ of SRCs were caused by equipment contact in boys' baseball (61.1\%), girls' softball (60.0\%), girls' volleyball (58.1\%), girls' lacrosse (57.1\%), and girls' field hockey (56.1\%). The majority of equipment contact-related SRCs across all sports resulted from contact with the ball (66.8\%). In total, 2.9\% of SRCs were reported to be recurrent. Within each sport, girls' field hockey reported the greatest proportion of SRC that were recurrent (4.5\%), followed by football (3.6\%) and girls' lacrosse (3.6\%).

Other apparent discrepancies in the rates of SRC include the number of sports examined, variance with sex, school or population size, and athlete-to-staff ratio all of which facilitates greater coverage at athletic events and increased rates of detection and reporting SRC.

\subsection{Clinicopathologic Correlation and Pathophysiology}

The AAN delineated the symptoms, clinical manifestations, and associated physical findings of SRC (Tables 1-4) that correlate well with neuroimaging [50]. In a series of investigations, Vagnozzi and colleagues [51] [52] [53] demonstrated that concussive injuries in general, were associated with a transient period of metabolic brain derangement as evidenced by the decrease in the cerebral concentration of $\mathrm{N}$-acetylaspartate through repeated ${ }^{1} \mathrm{H}-\mathrm{MR}$ spectroscopic studies to follow the course of recovery and the resolution of concussion-associated clinical symptoms.

Jantzen and colleagues [50] coupled functional MR with task-specific information to detect functional abnormalities associated with SRCs. A cohort of 
eight concussed male adult football players age 19 - 23 years underwent preseason baseline levels of blood oxygen level-dependent (BOLD) activity with contemporaneous testing of mathematical, memory, and sensorimotor coordination. With repeat of the studies within a week of a reported SRC, there was a marked increase in the amplitude and extent of BOLD activity in parietal and lateral frontal cortices and the cerebellum. These findings were consistent with the recruitment of additional neural resources compensating for the reduced processing efficiency caused by axonal damage following SRC.

Table 1. Frequently Observed Features of Sports-Related Concussion*.

Vacant state (befuddled facial expression)

Delayed verbal and motor responses (slow to answer questions or follow instructions)

Confusion and inability to focus attention (easily distracted and unable to follow through with normal activities)

Disorientation (walking in the wrong direction, unaware of time, date and place)

Slurred or incoherent speech (making disjointed or incomprehensible statements)

Gross observable incoordination (stumbling, inability to walk tandem/straight line)

Emotions out of proportion to circumstances (distraught, crying for no apparent reason)

Memory deficits (exhibited by repeatedly asking the same question that has already been answered, or inability to memorize and recall $3 / 3$ words or $3 / 3$ objects in 5 minutes)

Any period of loss of consciousness (unresponsive to arousal)

${ }^{*}$ Adapted from reference [26].

Table 2. Symptoms of Sports-Related Concussion*.

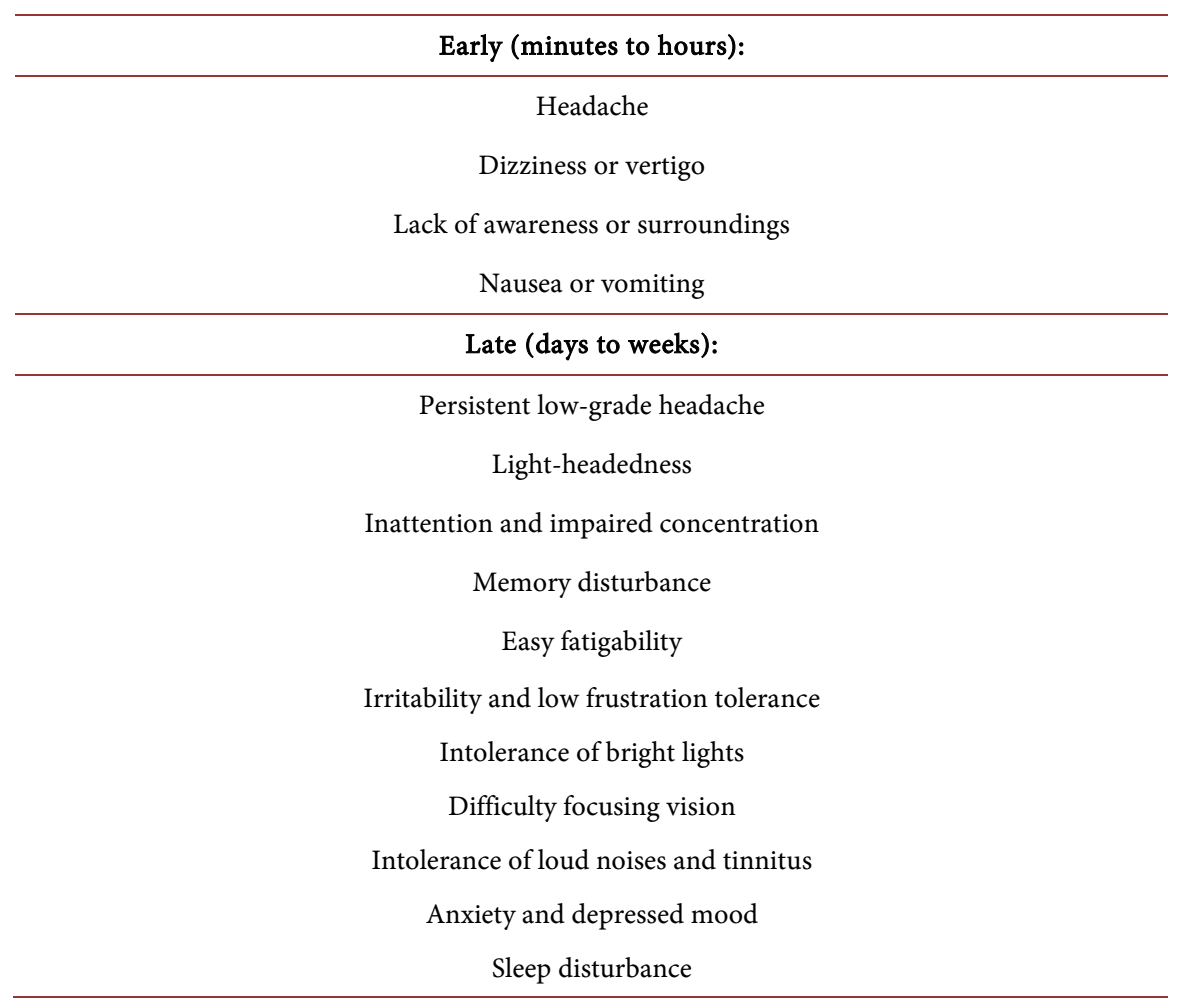

\footnotetext{
${ }^{\star}$ Adapted from reference [26].
} 
Table 3. Sideline Evaluation of Sports-Related Concussion*.

\begin{tabular}{cl}
\hline Mental Status Testing & \\
Observation: & $\begin{array}{l}\text { Appearance of associated abnormal symptoms (headaches, dizziness, } \\
\text { nausea, unsteadiness, photophobia, blurred or double vision, } \\
\text { emotional lability, and mental status changes) }\end{array}$ \\
Orientation: & Time, place, person, and situation (circumstances of injury) \\
Concentration & Reciting 3 - 5 digits backward \\
Memory & Recall of 3 word and 3 objects respectively at 0 and 5 minutes \\
Neurology Exam & \\
Pupils & Symmetry and reaction to light \\
Coordination & Finger-to-nose, tandem gait \\
Sensation & Finger-to-nose (eyes closed) and Romberg test \\
\hline
\end{tabular}

*Adapted from reference [26].

Table 4. Grading Scale for of Sports-Related Concussion*.

Grade 1: Transient confusion, no loss of consciousness, concussive symptoms or mental status abnormalities on examination resolve $<15$ minutes.

Grade 2: Transient confusion, no loss of consciousness, concussion symptoms or mental status abnormalities on examination last $>15$ minutes.

Grade 3: Any loss of consciousness, either seconds or minutes.

*Adapted from reference [26].

\subsection{Treatment}

Data have been insufficient to show that any intervention enhances recovery or diminishes long-term sequelae following SRC [31]. Winkler and Taylor [54] examined six studies of 421 young people/children concerning treatment of persistent symptoms following SRC or mTBI. Despite a wide variety of medical and nonmedical interventions, all studies reported positive results. However, all were limited in their design, and only one [55] was a controlled trial. Four studies were retrospective case series [56] [57] [58] [59], and only one was a prospective cohort study [60]. The natural history of SRCs is significant resolution of symptoms in the first 3 months after injury and further improvement by 12 months [24]. The changes observed in children and adolescents following treatment likely constitute the natural resolution of the symptoms and therefore cannot be attributed with certainty to the effect of any intervention.

\section{Section 2. Social-Ecological Model}

The SEF is a theoretical structure employed in public health to illustrate and understand how levels of society interact with a given health-related problem. The model itself is often presented with society and policy at the highest level, including stakeholders in policy development, dissemination, enforcement, evaluation and revision; followed by community; and below that, interpersonal 
relationships and intrapersonal factors of the athlete.

\subsection{Policy Level}

\subsubsection{State Legislation: Lystedt Laws}

A series of US state laws have improved recognition and side line management of SRC and vary state by state however, with the same three foundational directives [61]. The first is the education of coaches, parents, and athletes: Schools and sports leagues must inform and educate coaches, athletes, and their parents and guardians about concussion through training and a concussion information sheet. The second is removal from play. Athletes believed to have sustained a concussion or who exhibit signs, symptoms, or behaviors consistent with the injury are removed from practice and game play immediately. This third is permission to return-to-play (RTP). Athletes RTP only after 24 hours with written clearance from a licensed health care provider (LHCP) trained in concussion management. The differences between state laws vary as to the sport programs that must comply, the penalties for those that do not comply, and the designated LHCPs authorized to make RTP decisions. Several states have designated the written clearance to come only from a licensed physician while others have included language specifically allowing physician assistants, nurse practitioners, neuropsychologists, athletic trainers (AT), and physical therapists.

State concussion laws do not apply to summer resident or day camps, except those that run licensed sports programs. The American Camp Association (ACA), with its 11,000 members nationwide, conducted a 2006 sample of participating camps in a pilot illness and injury surveillance study that reported 1.15 adverse events per 1000 camper-days including concussion injuries [62]. The ACA's Healthy Camp Study Impact Report 2011 [63] cited 23.6\% of injuries to campers each season, and $18.5 \%$ of injuries to staff, altogether, in the head, face, and neck; making camps of all types a high-risk source of SRC.

Harvey and colleagues [64] applied a four-stage framework of engagement, enactment, research and reform of states' Lystedt Laws noting that public health lawmaking in this area was consistent with prior standard high-visibility public health law interventions such as mandatory seat-belt laws [65]. The first stage involves engaging the public and key stakeholders, asking them to rethink the role of government intervention into a previously under-regulated space [66] [67].

From 2009 to 2014, all states enacted some form of SRC laws [68] [69] as a response to this public health problem. This prompted a variety of research inquiries into their actual and potential effectiveness, some of which focused on the direct impact of such laws [70] [71] [72]. With all states engaged and researchers presenting their initial analyses of the consequences of such interventions, the fourth stage of substantive law reform has been occurring. Consistent with cycles in other public health areas, SRC legislation is entering a reform stage with state legislatures revisiting and revising them. Twenty-two states have 
made substantive changes to their laws since original enactment, and six states more than once, while others are likely to follow suit [72] [73].

Efforts to evaluate the impact of concussion legislation on concussion rates and health care utilization have generally reported positive results. One study [74] found that the number of documented SRCs more than doubled in Seattle public schools after the enactment of the Lystedt Law. Another study [75] concluded that concussion legislation resulted in an increase in health care utilization, with states that have SRC legislation demonstrating a $10 \%$ higher concussion-related health services utilization rate compared to the ones without such laws.

\subsubsection{School Policy: Implementation and Compliance}

Whereas it is essential to understand the positive impact of concussion legislation, it is equally important to understand the implementation of, and compliance with these laws in schools, as their effectiveness relates to implementation. New York State's (NYS) Lystedt Law, was passed in 2011, and went into effect July 1, 2012. Kajankova and colleagues [76] evaluated the implementation of NYS's SRC law at the district level by identifying gaps in the written concussion policies. Participants were a sample of NYS school districts $(\mathrm{N}=47)$ that provided their written concussion participant and procedures ( $\mathrm{P} \& \mathrm{P})$ documents. In 2013, under the Freedom of Information Act, 52 districts (47 Westchester County and 5 large city school districts across NYS (Albany, NYC, Buffalo, Syracuse, and Rochester) were queried as to their management of P\&P documents mandated for compliance with the State's 2012 Concussion Awareness and Management Act ("the Act"). By the end of 2013, 89\% (42/47) of the districts in Westchester County and 100\% (5/5) of the large city districts that provided their written concussion management $\mathrm{P} \& \mathrm{P}$ documents resulted in a total sample of 47 NYS school districts.

The authors [76] divided the Act into 4 broad sections, each of which was broken down into 27 individual items in total. They included formal concussion education and instruction of school personnel (Concussion Education for School Personnel [10 items]); dissemination of concussion information to parents or guardians (Parent Concussion Information [8 items]); the concussion team and their responsibilities (Concussion Team [3 items]); and concussion management procedures [Concussion Management [6 items]). Raters coded districts as "compliant" or "not compliant" with the 27 items. A district was "compliant" with an item if it mentioned in the P\&P documents. There was a significantly higher wealth ratio in outer Westchester County compared to large city districts (1.63 vs. 0.44 ), with fewer students (3759 vs. 222,612$)$ and increased annual expenditure per pupil $(\$ 26,229$ vs. $\$ 20,236)$. Yet Westchester County districts varied in their compliance with the 27 required items, with rates ranging from $30 \%$ to $100 \%$ (mean $=76 \%$; median $=83 \%$ ) in comparison to less variable, and more compliant, urban districts, with rates ranging from $81 \%$ to $96 \%$ (mean $=88 \%$; median $=85 \%)$. Westchester County and large city districts were similar in two 
areas of lowest compliance including the provision of information relating to concussion in the any interscholastic sports permission form to a parent or guardian (36\% versus 20\%); and authorization for a licensed physician to resume athletic activity kept on file in the student's permanent health record (50\% vs $60 \%)$.

A review of compliance by sections of the Act in this study [76] revealed that all districts were generally more compliant with section 1 (Concussion Education for School Personnel), requiring concussion training and education for key personnel, than with other sections. While most districts were compliant in providing their staff with information regarding SRCs, they were inadequate in managing concussions once they occurred. The effective tracking of SRCs in schools requires a reporting process. However, the law does not require medical professionals, tasked with evaluating children after a concussion, to train in brain injury, which can have negative short- and long-term consequences. The Act also does not adequately address the tracking of concussed students and their ongoing symptoms and long-term outcomes. The fact that no district in the study by Kajankova and colleagues [76] achieved a 100\% compliance rate indicates obvious gaps in implementation of the Act within NYS school districts. As full implementation of the Act is essential to its effectiveness, these gaps raise concerns regarding the quality of prevention and management efforts at the school level.

Thus, there is an obvious need for interventions aimed at increasing overall compliance and surveillance to ensure adequate implementation of the Act. It is necessary to identify all possible barriers to implementing the law and fully address concussions. The Act only identifies certain school personnel that are required to be educated about concussions. All school personnel should be knowledgeable about the requirements of the Act and possess basic knowledge about the management of concussion. Widespread training of personnel about concussions would be valuable, as most school personnel will play a role in helping to prevent or manage concussions in the classroom, during sports, and other school activities. This could be achieved through a yearly in-service for all school personnel, and could include information about the requirements of the Act, the related policies developed by the school, and basic information about the causes of concussions and how to best manage SRCs once they occur.

It is important to note that enacted legislative and educational policies represent the minimum acceptable standard. Individual schools, districts, conferences, or sports can implement procedures that go beyond the general requirements of the higher-level policy. Policy at all levels have been influenced by professional organizations such as the American Academy of Pediatrics, the Council on Sports Medicine and Fitness, Institute of Medicine, State Medical Societies, AAN, the American College of Sports Medicine, the American Medical Association, and NFL [4] [15] [31] [77] [78] [79] [80]. Education on these policies and the positions of these organizations is necessary so that all stakeholders 
involved in a sport setting, including administrators, coaches, parents, and athletes, understand the policies and their role in ensuring compliance with the policies.

\subsection{Community Level}

A community is a group of people with diverse characteristics linked by social ties, who share common perspectives, and engage in joint action in a common geographical location or setting [81]. Communities have linked social ties that form key components in the perceptions of the culture of sports. Community perceptions likewise drive team behaviors. While colleges and teams at the National Collegiate Athletic Association (NCAA) level are required to have an AT and team physician, this is not required at the secondary school level and one is rarely available on site. Athletic trainers are not consistently present at secondary school practices and games to mitigate the health risks of SRC. A cross-sectional study of 8509 US public secondary schools [82] surveyed from 2011 to 2013 reported that 70\% had AT services, including full-time (37\%), part-time (31\%), and per diem (2\%) AT services, while $27 \%$ had AT services from a hospital or physical therapy clinic. Athletic training services were available in $48 \%$ of schools at all sports practices. Few investigators have directly studied how staffing influences prevention, exposure, and injury outcomes of SRC. There is reason to believe that full-time ATs are generally able to identify and care for more students with injuries.

Among 44 ATs who responded in a cross-sectional study using data from the National Athletic Treatment Injury and Outcomes Network about their employment setting, $31 \%$ were full-time employees of the high school, and $68 \%$ as outreach ATs (i.e., full-time and part-time ATs from nearby clinics, hospitals, and graduate school programs] [83]. Athletic trainers who were full-time high school employees reported a higher overall football injury rate than outreach ATs (29.7 versus 8.2 per 1000 athletic events $(\mathrm{AE})$; $\mathrm{RR}=3.6 ; 95 \% \mathrm{CI}=3.4,3.9$ ). The average number of AT services reported per football injury by ATs who were full-time high school employees $(9.9 \pm 21.8)$ was larger than that reported by outreach ATs $(5.2 \pm 8.3 ; P<0.001)$. Onsite ATs may see more collisions that require a full evaluation, leading to more concussion diagnoses. While medical professionals serve as an appropriate authority to whom an athlete can report a potential SRC, a present AT may also influence reporting indirectly by helping to foster a trusting patient-provider relationship that results in athletes more comfortable in seeking care for suspected injuries. Moreover, ATs provide increased emphasis on SRC safety and the importance of reporting suspected injuries.

Other important contributors to the community and other levels in the SEF are the media and local organizations. Two examples are the Brain Injury Association of New York State (https://bianys.org/), a community-based model for concussion management, abbreviated REAP for Reduce, Educate Accommodate 
and Pace, providing advocacy, family counseling, and on-line training services to student athletes seen in ED for concussion. Another is the CDC's on-line Heads Up to Youth Sports Program designed to educate parents, coaches, sports officials, and student athletes about SRC prevention

(https://www.cdc.gov/headsup/youthsports/index.html); and toolkits for high school coaches and physicians. Sarmiento and colleagues [84] analyzed the result of a mailed questionnaire to eligible high school coaches who received the tool kit noting that respondents self-reported favorable changes in knowledge, attitudes, and practices toward the prevention and management of concussions. Chrisman and colleagues [85] found that physicians who received a mailed toolkit in the intervention group designed to increase knowledge about concussion were overall less likely to recommend next day return to play after a concussion (adjusted $\mathrm{OR}=0.31,95 \% \mathrm{CI}=0.12-0.76$ ) than controls.

\subsection{Interpersonal and Intrapersonal Levels}

The interpersonal level encompasses the interactions that athletes have with others in their lives. Coaches and medical providers discussed in the previous section provide normative references for behaviors in regards to sports and detection and treatment of concussion. Teammates may also play an important role in the early identification and reporting of SRC as perceived norms, shaped by observations of, and interactions with, members of the referent population. Kroshus and colleagues [86] noted that in regards to SRC-reporting norms, athletes tended to think that they had safer attitudes than their teammates. Perceived norms were associated with symptom reporting intention, independent of the team's objective reporting norm. A social norms approach to SRC education, in which misperceived group norms are corrected and shifted in the direction of safety, is an important avenue for program development and evaluation research aimed at the secondary prevention of harm from SRC. A strategy that engages coaches and teammates in setting safe injunctive team norms, and that gives a voice to all team members, can have the benefit of disrupting the spiral of silence that helps perpetuate misperceived norms and could help in shifting true norms in the direction of SRC safety.

Kroshus and colleagues [87] studied 328 US collegiate athletes from four regionally competitive colleges located in the northeast, all engaged in NCAA in contact or collision sports other than football and ice hockey, sports which while perhaps having a lower public profile in the discussion of concussion risk, with nonetheless an elevated risk of concussion. Even at the college level, when most athletes lived away from home, there was pressure from teammates (13.26\%), coaches (13.68\%), parents $(9.42 \%)$, and fans $(8.12 \%)$ not to report SRCs, with $26.5 \%$ of athletes acknowledging such pressures in the prior season from at least one of those four sources. Athletes who experience pressure from multiple sources, not just from coaches and teammates but also from parents and fans, had a lower concussion reporting intention than athletes who only experienced 
pressure from coaches and teammates. Appropriate SRC education for athletes developed in conjunction with interventions at the other levels of the SEF sets the stage for the transfer and sustainability of the information and skills that integrate at the athlete's level.

Concussion education for athletes has the potential to play a role in reducing the health burden of concussions from sport by modifying individual risk-related behaviors. Kroshus and Baugh [88] analyzed data collected from AT and collegiate athletes at NCAA member institutions noting that $91.3 \%$ of ATs were involved in delivering concussion education. With $80 \%$ of athletes indicating that they received educational information from their school about concussion, their preferences for concussion education were from ATs (83.1\%), physicians (54.5\%), or coaches $(40.9 \%)$, covering symptoms $(89.0 \%)$, including, the proper management (84.9\%), possible long-term consequences (84.5\%), impact on athletic (87.0\%), academic performance (86.1\%), and the importance of reporting SRC symptoms (82.6\%).

\section{Section 3. Recommendations}

The current systems of health care have challenges and inconsistencies leading to gaps in service. The optimal management of childhood SRC requires care that goes beyond the acute injury, and into the school setting to maximize academic and social outcomes. This is more likely to occur when healthcare and educational systems are optimally coordinated. The current systems of care leads to gaps in optimal care of children with a SRC, especially when failing to be identified by school staff, or inconsistencies in communicating medical information regarding school modifications, follow-up health services, or concussion-related educational services. Children who sustain SRC at different ages face different challenges. Young children face increased vulnerability due to concomitant maturational periods of brain and neuropsychological development, whereas older adolescents in higher grades face greater demands on cognitive, organization, and problem solving skills due to deficits in executive functioning. Educational issues that emerge later related to concussion may be inappropriately managed or incorrectly attributed to other factors.

The solution begins with identifying concussion at the time of injury and receiving proper assessment by trained personnel. Athletes suspected of SRC by self-report, or after a side line evaluation should be removed from play and reported to the school according to state law. Obtaining prompt medical care by a licensed health care provider, knowledgeable in SRC and mTBI, who relates the findings to school officials, will ensure consistency in healthcare and educational services. There is insufficient evidence to support the use of neuropsychological testing in preadolescents [31]; however, paper-and-pencil or computer techniques that test memory, reaction time, and speed of cognitive processing, will identify SRC in $71 \%$ to $88 \%$ of affected older adolescent athletes remote from the injurious event. A combination of diagnostic tests as compared with individual 
tests is likely to improve diagnostic accuracy of concussion [31]. Neuroimaging employing brain CT or MRI does not diagnose a SRC, but may rule out serious head injuries associated with complicated mTBI, and severe PCS. Children with neurocognitive and neuropsychological deficits benefit from specialty evaluations to determine appropriate outpatient services and school follow-up assessments.

Viewing SRC through the lens of a public health SEF, clarifies the actors and social and environmental factors relevant to this program, and identifies areas amenable to intervention and health risk mitigation of SRC in school-age at-risk youth. At the societal and policy level, state laws mandating education, removal from play to minimize further injury, and elucidating the roles of school personnel in reporting and managing suspected SRC, all are important steps forward. Individuals supervising young school age athletes with an empiric diagnosis of a SRC should be managed conservatively as regards RTP. Legislative and educational policies represent the minimum acceptable standard. Individual school districts, schools, and team personnel demonstrate differing levels of compliance to the legal statutes, often independent of financial means. At the community and personal levels, the healthy social ties that form between LHCPs, school-based professionals, ATs, teammates, and parents drive the interest in understanding SRC, including its reporting and prevention by avoiding secondary injuries and reinforcing healthy behaviors. LHCPs should educate school-based professionals and school systems about the risks of experiencing a concussion so that they may provide accurate information to parents and athletes.

\section{Suggested Research}

There are at least four areas of research needed to fill the gap in our understanding of SRC and $\mathrm{mTBI}$ in adolescents. First, the further investigations of the pathophysiology of SRC and mTBI, notably the neuroinflammatory mechanisms that may contribute to the brain dysfunction at the molecular and neurochemical levels (http://www.davidsyounger.com/blog/expanding-horizons-tbi).

Second, further insight into the optimal medical management of SRC. With evidence-based data failing to show any intervention to enhance recovery or diminish long-term sequelae [31], and no standard of care for its short-term and long-term management, there is an urgent unmet need for RCTs that focus on subpopulations of children affected by SRC, and go beyond side-line management to develop meaningful treatment strategies.

Third, a focus on the prevalence and longitudinal outcome of children who enter schools each fall with a diagnosis of a SRC or another mTBI. Well-designed, school-based epidemiologic studies will answer this need. In the meantime, a simple question added to the health forms of entering students each fall querying their history of lifetime and recent concussions provide a useful starting point.

Fourth, understanding the contribution of resident and summer day camps to 
$S R C$. With a quarter of campers sustaining a head injury including SRC each season in one of the 11,000 members ACA camps [64], there are hundreds of thousands of children attending camp before the start of school in the fall at risk for undiagnosed SRC excluded from state-mandated reporting. Epidemiologic studies are needed to estimate the burden of SRC among this large adolescent cohort.

\section{References}

[1] Mitsis, E.M., Riggio, S., Kostakoglu, L., et al. (2014) Tauopathy PET and Amyloid PET in the Diagnosis of Chronic Traumatic Encephalopathies: Studies of a Retired NFL Player and of a Man with FTD and a Severe Head Injury. Translational Psychiatry, 4, e441. https://doi.org/10.1038/tp.2014.91

[2] Omalu, B., Small, G.W., Bailes, J., et al. (2017) Postmortem Autopsy-Confirmation of Antemortem [F-18] FDDNP-PET Scans in a Football Player with Chronic Traumatic Encephalopathy. Neurosurgery, 10, 1-10.

[3] Branch, J. (2017) On the Table, the Brain Appeared Normal. New York Times, November $10, \mathrm{~B} 9$.

[4] Institute of Medicine, National Research Council of the National Academies (2015) Sports-Related Concussions in Youth: Improving the Science, Changing the Culture. Military Medicine, 180, 123-125. https://doi.org/10.7205/MILMED-D-14-00516

[5] Ilie, G., Boak, A., Adlaf, E.M., et al. (2013) Prevalence and Correlates of Traumatic Brain Injuries among Adolescents. JAMA, 309, 1-2. https://doi.org/10.1001/jama.2013.6750

[6] Lerner, E.B. and Moscati, R.M. (2001) The Golden Hour: Scientific Fact or Medical "Urban Legend"? Academic Emergency Medicine, 8, 758-760. https://doi.org/10.1111/j.1553-2712.2001.tb00201.x

[7] Teasdale, G.M. and Jennett, B. (1974) Assessment of Coma and Impaired Consciousness: A Practical Scale. The Lancet, 2, 81-84. https://doi.org/10.1016/S0140-6736(74)91639-0

[8] Foulkes, M.A., Eisenberg, H.M., Jane, J.A. and the Traumatic Coma Data Bank Research Group (1991) The Traumatic Coma Data Bank: Design, Methods, and Baseline Characteristics. Journal of Neurosurgery, 75, S8-S13.

[9] Rimel, R.W., Giordani, B., Barth, J.T., et al. (1981) Disability Caused by Minor Head Injury. Neurosurgery, 9, 221-228.

[10] Barth, J.T., Macciocchi, S.N., Boll, T.J., et al. (1983) Neuropsychological Sequelae of Minor Head Injury. Neurosurgery, 13, 529-533. https://doi.org/10.1227/00006123-198311000-00008

[11] Gennarelli, T.A., Thibault, L.E., Adams, J.H., et al. (1982) Diffuse Axonal Injury and Traumatic Coma in the Primate. Annals of Neurology, 12, 564-575. https://doi.org/10.1002/ana.410120611

[12] Oppenheimer, D.R. (1968) Microscopic Lesions in the Brain Following Head Injury. Journal of Neurology, Neurosurgery, and Psychiatry, 31, 299-306. https://doi.org/10.1136/jnnp.31.4.299

[13] Tellier, A., Della Malva, L.C., Cwinn, A., et al. (1999) Mild Head Injury: A Misnomer. Brain Injury, 13, 463-475.

[14] Miller, J.D., Murray, L.S. and Teasdale, G.M. (1990) Development of a Traumatic 
Intracranial Haematoma after a "Minor" Head Injury. Neurosurgery, 27, 669-673. https://doi.org/10.1227/00006123-199011000-00001

[15] Halstead, M.E., Walter, K.D. and the Council on Sports Medicine and Fitness (2010) Clinical Report-Sports Related Concussion in Children and Adolescents. Pediatrics, 126, 597-615. https://doi.org/10.1542/peds.2010-2005

[16] Lee, B. and Newberg, A. (2005) Neuroimaging in Traumatic Brain Imaging. NeuroRx, 2, 372-383. https://doi.org/10.1602/neurorx.2.2.372

[17] Wide, E.A., McCauley, S.R., Hunter, J.V., et al. (2008) Diffusion Tensor Imaging of Acute Mild Traumatic Brain Injury in Adolescents. Neurology, 70, 948-955. https://doi.org/10.1212/01.wnl.0000305961.68029.54

[18] DeMatteo, C.A., Hanna, S.E., Mahoney, W.J., et al. (2010) My Child Doesn't Have a Brain Injury, He Only Has a Concussion. Pediatrics, 125, 327-334. https://doi.org/10.1542/peds.2008-2720

[19] Centers for Disease Control and Prevention (2011) Nonfatal Traumatic Brain Injuries Related to Sports and Recreation Activities among Persons Aged $\leq 19$ Years-United States, 2001-2009. Morbidity and Mortality Weekly Report, 60, 1337-1342.

[20] Veliz, P., McCabe, S.E., Eckner, J.T., et al. (2017) Prevalence of Concussion among US Adolescents and Correlated Factors [Letter]. JAMA, 318, 1180-1182. https://doi.org/10.1001/jama.2017.9087

[21] Ilie, G., Boak, A., Adlaf, E.M., et al. (2013) Prevalence and Correlates of Traumatic Brain Injuries among Adolescents. JAMA, 309, 2550-2552. https://doi.org/10.1001/jama.2013.6750

[22] Centers for Disease Control and Prevention. TBI Data and Statistics: Emergency Department Visits, Hospitalizations and Deaths, 2001-2010.

https://www-cdc-gov.proxy.library.nyu.edu/traumaticbraininjury/data/index.html

[23] Katz, D.I., Cohen, S.I. and Alexander, M.P. (2015) Mild Traumatic Brain Injury. Handbook of Clinical Neurology, 127, 131-156. https://doi.org/10.1016/B978-0-444-52892-6.00009-X

[24] Barlow, K.M., Crawford, S., Stevenson, A., et al. (2010) Epidemiology of Postconcussion Syndrome in Pediatric Mild Traumatic Brain Injury. Pediatrics, 126, e374-e381. https://doi.org/10.1542/peds.2009-0925

[25] American Congress of Rehabilitation Medicine, Brain Injury Interdisciplinary Special Interest Group, Disorders of Consciousness Task Force (1993) Definition of Mild Traumatic Brain Injury. The Journal of Head Trauma Rehabilitation, 8, 86-87. https://doi.org/10.1097/00001199-199309000-00010

[26] American Academy of Neurology Practice Parameter: The Management of Concussion in Sports (Summary Statement) (1997) Report of the Quality Standards Subcommittee. Neurology, 48, 581-585. https://doi.org/10.1212/WNL.48.3.581

[27] National Center for Injury Prevention and Control (2003) Report to Congress on Mild Traumatic Brain Injury in the United States: Steps to Prevent a Serious Public Health Problem. Centers for Disease Control and Prevention, Atlanta.

[28] Caroll, L.J., Cassidy, J.D., Holm, L., et al. (2004) Methodological Issues and Research Recommendations for Mild Traumatic Brain Injury: The WHO Collaborating Centre Task Force on Mild Traumatic Brain Injury. Journal of Rehabilitation Medicine, 43, 113-125. https://doi.org/10.1080/16501960410023877

[29] Fann, J.R., Burington, B., Leonetti, A.J., et al. (2004) Psychiatric Illness Following Traumatic Brain Injury in an Adult Health Maintenance Organization Population. 
Archives of General Psychiatry, 61, 53-56. https://doi.org/10.1001/archpsyc.61.1.53

[30] Department of Veterans Affairs (2009) Clinical Practice Guideline: Management of Concussion/Mild Traumatic Brain Injury. Department of Veterans Affairs, DOD, Washington DC.

[31] Giza, C.C., Kutcher, J.S., Ashwal, S., et al. (2013) Summary of Evidence-Based Guideline Update: Evaluation and Management of Concussion in Sports: Report of the Guideline Development Subcommittee of the American Academy of Neurology. Neurology, 80, 2250-2257. https://doi.org/10.1212/WNL.0b013e31828d57dd

[32] Williams, H., Levin, H.S. and Eisenberg, H.M. (1990) Mild Head Injury Classification. Neurosurgery, 27, 422-428. https://doi.org/10.1227/00006123-199009000-00014

[33] Ruff, R. (2005) Two Decades of Advances in Understanding of Mild Traumatic Brain Injury. The Journal of Head Trauma Rehabilitation, 20, 5-18. https://doi.org/10.1097/00001199-200501000-00003

[34] BlueCross BlueShield (2017) The Health of America Report. The Steep Rise in Concussion Diagnosis in the U.S. Blue Health Intelligence, 1-8.

[35] Gerberich, S.G., Priest, J.D., Boen, J.R., et al. (1983) Concussion Incidences and Severity in Secondary School Varsity Football Players. AJPH, 73, 1370-1375. https://doi.org/10.2105/AJPH.73.12.1370

[36] Powell, J.W. and Barber-Foss, K.D. (1999) Traumatic Brain Injury in High School Athletes. JAMA, 282, 958-963. https://doi.org/10.1001/jama.282.10.958

[37] Lovell, M.R. and Collins, H.W. (1998) Neuropsychological Assessment of the College Football Player. The Journal of Head Trauma Rehabilitation, 13, 9-26. https://doi.org/10.1097/00001199-199804000-00004

[38] Centers for Disease Control and Prevention (1997) Traumatic Brain Injury-Colorado, Missouri, Oklahoma, and Utah, 1990-1993. Morbidity and Mortality Weekly Report, 46, 8-11.

[39] Coronado, V.G., Haileyesus, T., Cheng, T.A., et al. (2015) Trends in Sports- and Recreation-Related Traumatic Brain Injuries Treated in US Emergency Departments: The National Electronic Injury Surveillance System-All Injury Program (NEISS-AIP) 2001-2012. The Journal of Head Trauma Rehabilitation, 30, 185-197. https://doi.org/10.1097/HTR.0000000000000156

[40] Ilie, G., Mann, R.E., Hamilton, H., et al. (2015) Substance Use and Related Harms among Adolescents with and without Traumatic Brain Injury. The Journal of Head Trauma Rehabilitation, 30, 293-301. https://doi.org/10.1097/HTR.0000000000000101

[41] Gessel, L.M., Fields, S.K., Collins, C.L., et al. (2007) Concussions among Unites States High School and Collegiate Athletes. Journal of Athletic Training, 42, 495-503.

[42] Barlow, M., Schlabach, D., Peiffer, J., et al. (2011) Differences in Change Scores and Predictive Validity of Three Commonly used Measures Following Concussion in the Middle School and High School Aged Population. International Journal of Sports Physical Therapy, 6, 150-157.

[43] Makdissi, M., Cantu, R.C., Johnston, K.M., et al. (2013) The Difficult Concussion Patient: What Is the Best Approach to Investigation and Management of Persistent (>10 Days) Postconcussion Symptoms? British Journal of Sports Medicine, 47, 308-313. https://doi.org/10.1136/bjsports-2013-092255

[44] Meehan, W.P. III, d'Hemecourt, P. and Comstock, R.D. (2010) High School Con- 
cussions in the 2008-2009 Academic Year: Mechanism, Symptoms, and Management. The American Journal of Sports Medicine, 38, 2405-2409. https://doi.org/10.1177/0363546510376737

[45] Yeates, K.O., Taylor, H.G., Rusin, J., et al. (2012) Premorbid Child and Family Functioning as Predictors of Post-Concussion Symptoms in Children with Mild Traumatic Brain Injuries. International Journal of Developmental Neuroscience, 30, 231-237. https://doi.org/10.1016/j.ijdevneu.2011.05.008

[46] Morgan, C.D., Zuckerman, S.L., Lee, Y.M., et al. (2015) Predictors of Postconcussion Syndrome after Sports-Related Concussion in Young Athletes: A Matched Case-Control Study. Journal of Neurosurgery: Pediatrics, 15, 589-598. https://doi.org/10.3171/2014.10.PEDS14356

[47] Olsson, K.A., Lloyd, O.T., Lebrocque, R.M., et al. (2013) Predictors of Child-Post-Concussion Symptoms at 6 and 18 Months Following Mild Traumatic Brain Injury. Brain Injury, 27, 145-157. https://doi.org/10.3109/02699052.2012.729286

[48] Ponsford, J., Willmott, C., Rothwell, A., et al. (1999) Cognitive and Behavioral Outcome Following, Mild Traumatic Head Injury in Children. The Journal of Head Trauma Rehabilitation, 14, 360-372. https://doi.org/10.1097/00001199-199908000-00005

[49] O'Connor, K.L., Baker, M.M., Dalton, S.L., et al. (2017) Epidemiology of Sports-Related Concussions in High School Athletes: National Athletic Treatment, Injury and Outcomes Network (NATION), 2011-2012 through 2013-2014. Journal of Athletic Training, 52, 175-185. https://doi.org/10.4085/1062-6050-52.1.15

[50] Jantzen, K.J., Anderson, B., Steinberg, F.L., et al. (2004) A Prospective Functional MR Imaging Study of Mild Traumatic Brain Injury in College Football Players. American Journal of Neuroradiology, 25, 738-745.

[51] Vagnozzi, R., Signoretti, S., Floris, R., et al. (2013) Decrease in N-Acetylaspartate Following Concussion May Be Coupled to Decrease in Creatine. The Journal of Head Trauma Rehabilitation, 28, 284-292. https://doi.org/10.1097/HTR.0b013e3182795045

[52] Vagnozzi, R., Signoretti, S., Tavazzi, B., et al. (2008) Temporal Window of Metabolic Brain Vulnerability to Concussion: A Pilot 1H-Magnetic Resonance Spectroscopic Study in Concussed Athletes, Part III. Neurosurgery, 62, 1286-1295.

[53] Vognozzi, R., Signoretti, S., Cristofori, L., et al. (2010) Assessment of Metabolic Brain Damage and Recovery Following Mild Traumatic Brain Injury: A Multicenter, Proton Magnetic Resonance Spectroscopic Study in Concussed Patients. Brain, 133, 3232-3242. https://doi.org/10.1093/brain/awq200

[54] Winkler, R. and Taylor, N.F. (2015) Do Children and Adolescents with Mild Traumatic Brain Injury and Persistent Symptoms Benefit from Treatment? A Systematic Review. The Journal of Head Trauma Rehabilitation, 30, 324-333. https://doi.org/10.1097/HTR.0000000000000114

[55] Ponsford, J., Willmott, C., Rothwell, A., et al. (2001) Impact of Early Intervention on Outcome after Mild Traumatic Brain Injury in Children. Pediatrics, 108, 1297-1303. https://doi.org/10.1542/peds.108.6.1297

[56] Gagnon, I., Galli, C., Friedman, D., et al. (2009) Active Rehabilitation for Children Who Are Slow to Recover Following Sport-Related Concussion. Brain Injury, 23, 956-964. https://doi.org/10.3109/02699050903373477

[57] Kuczynski, A., Crawford, S., Bodell, L., et al. (2013) Characteristics of Posttraumatic Headaches in Children Following Mild Traumatic Brain Injury and Their Response 
to Treatment: A Prospective Cohort. Developmental Medicine \& Child Neurology, 55, 636-641. https://doi.org/10.1111/dmcn.12152

[58] Moser, R.S., Glatts, C. and Schatz, P. (2012) Efficacy of Immediate and Delayed Cognitive and Physical Rest for Treatment of Sports-Related Concussion. Journal of Pediatrics, 161, 922-926. https://doi.org/10.1016/j.jpeds.2012.04.012

[59] Pinchuk, D., Pinchuk, O., Sirbiladze, K., et al. (2013) Clinical Effectiveness of Primary and Secondary Headache Treatment by Transcranial Direct Current Stimulation. Frontiers in Neurology, 4, 25. https://doi.org/10.3389/fneur.2013.00025

[60] Falk, A.-C. (2013) A Nurse-Led Paediatric Head Injury Follow-Up Service. Scandinavian Journal of Caring Sciences, 27, 51-56. https://doi.org/10.1111/j.1471-6712.2012.00999.x

[61] Concannon, L.G. (2016) Effects of Legislation on Sports-Related Concussion. Physical Medicine \& Rehabilitation Clinics of North America, 27, 513-527. https://doi.org/10.1016/j.pmr.2015.12.006

[62] Yard, E.E., Scanlin, M.M., Erceg, E.L., et al. (2006) Illness and Injury among Children Attending Summer Camp in the United States. Pediatrics, 118, e1342-e1349. https://doi.org/10.1542/peds.2006-0834

[63] American Camp Association. The Healthy Camp Study. Impact Report 2006-2010. https://s3.amazonaws.com/amo_hub_content/Association1124/files/Healthy\%20Ca mp\%20Study\%20Impact\%20Report.pdf

[64] Harvey, H.H., Koller, D.L. and Lowrey, K.M. (2015) The Four Stages of Youth Sports TBI Policymaking: Engage, Enactment, Research, and Reform. The Journal of Law, Medicine \& Ethics, 43, 87-90. https://doi.org/10.1111/jlme.12225

[65] Harper, S., et al. (2014) The Effect of Mandatory Seat Belt Laws on Seat Belt Use by Socioeconomic Position. Journal of Policy Analysis and Management, 33, 1141-1161. https://doi.org/10.1002/pam.21735

[66] Protecting Student Athletes from Concussions Act of 2013, S. 113th Congress, 1546.

[67] Pa, E.D. (2012) National Football League Players' Concussion Injury Litigation, MDL No. 2323. In Re: NCAA Student-Athlete Concussion Injury Litigation MDL No. 2492, N.D.Ill. 2013.

[68] National Federation of State High School Associations (2013) 2012-13 High School Athletics Participation Survey. In: NFHS Handbook 2013-2014. http://www.nfhs.org/media/885654/2013-14-nfhs-handbook.pdf

[69] Harvey, H.H. (2013) Reducing Traumatic Brain Injuries in Youth Sports: Youth Sports Traumatic Brain Injury State Laws, January 2009-December 2012. American Journal of Public Health, 103, 1249-1254. https://doi.org/10.2105/AJPH.2012.301107

[70] Chrisman, S.P., Schiff, M.A., Chung, S.K., et al. (2014) Implementation of Concussion Legislation and Extent of Concussion Education for Athletes, Parents, and Coaches in Washington State. The American Journal of Sports Medicine, 42, 1190-1196. https://doi.org/10.1177/0363546513519073

[71] Harvey, H.H. (2014) Refereeing the Public Health. Yale Journal of Health Policy, Law, and Ethics, 14, 66-121.

[72] Lowrey, K.M. and Morain, S.R. (2014) State Experiences Implementing Youth Sports Concussion Laws: Challenges, Successes, and Lessons for Evaluating Impact. The Journal of Law, Medicine \& Ethics, 42, 290-296. https://doi.org/10.1111/jlme.12146

[73] Lowrey, K.M. (2014) State Laws Addressing Youth Sports Related Traumatic Brain 
Injury and the Future of Concussion Law and Policy. Journal of Business \& Technology Law, 10, 61-72.

[74] Bompadre, V., Jinguji, T.M., Yanez, N.D., et al. (2014) Washington State's Lystedt Law in Concussion Documentation in Seattle Public High Schools. Journal of Athletic Training, 49, 486-492. https://doi.org/10.4085/1062-6050-49.3.30

[75] Gibson, T.B., Herring, S.A., Kutcher, J.S., et al. (2015) Analyzing the Effect of State Legislation on Health Care Utilization for Children with Concussion. JAMA Pediatrics, 169, 163-168. https://doi.org/10.1001/jamapediatrics.2014.2320

[76] Kajankova, M., Oswald, J.M., Terranova, L.M., et al. (2017) Response of School Districts to the New York State Concussion Awareness and Management Act: Review of Policies and Procedures. Journal of School Health, 87, 409-415. https://doi.org/10.1111/josh.12508

[77] Report of the Sports Medicine Committee (1990) Guidelines for the Management of Concussion in Sports. Colorado Medical Society, Class III.

[78] Herring, S.A., Cantu, R.C., Guskiewicz, K.M., et al. (2011) Concussion (Mild Traumatic Brain Injury) and the Team Physician: A Consensus Statement-2011 Update. Medicine and Science in Sports and Exercise, 43, 2412-2422. https://doi.org/10.1249/MSS.0b013e3182342e64

[79] Kelly, J.P., Nichols, J.S., Filley, C.M., et al. (1991) Concussion in Sports. Guidelines for the Prevention of Catastrophic Outcome. JAMA, 266, 2867-2869.

https://doi.org/10.1001/jama.1991.03470200079039

[80] Yengo-Kahn, A.M., Johnson, D.J. and Zuckerman, S.L. (2016) Concussions in the National Football League: A Current Concepts Review. The American Journal of Sports Medicine, 44, 801-811. https://doi.org/10.1177/0363546515580313

[81] MacQueen, K.M., McLellan, E., Metzger, D.S., et al. (2001) What Is Community? An Evidence-Based Definition for Participatory Public Health. American Journal of Public Health, 91, 1929-1938. https://doi.org/10.2105/AJPH.91.12.1929

[82] Pryor, R.R., Casa, D.J., Vandermark, L.W., et al. (2015) Athletic Training Services in Public Secondary Schools: A Benchmark Study. Journal of Athletic Training, 50, 156-162. https://doi.org/10.4085/1062-6050-50.2.03

[83] Kerr, Z.Y., Lynall, R., Mauntel, T.C., et al. (2016) High School Football Injury Rates and Services by Athletic Trainer Employment Status. Journal of Athletic Training, 51, 70-73. https://doi.org/10.4085/1062-6050-51.3.02

[84] Sarmiento, K., Mitchko, J., Klein, C.J., et al. (2010) Evaluation of the Centers for Disease Control and Prevention's Concussion Initiative for High School Coaches: "Heads Up: Concussion in High School Sports". School Health, 80, 112-118. https://doi.org/10.1111/j.1746-1561.2010.00491.x

[85] Chrisman, S.P., Schiff, M.A. and Rivara, F.P. (2011) Physician Concussion Knowledge and the Effect of Mailing the CDC's "Heads Up" Toolkit. Clinical Pediatrics, 50, 1031-1039. https://doi.org/10.1177/0009922811410970

[86] Kroshus, E., Garnett, B.R., Baugh, C.M., et al. (2015) Social Norms Theory and Concussion Education. Health Education Research, 30, 1004-1013. https://doi.org/10.1093/her/cyv047

[87] Kroshus, E., Garnett, B., Hawrilenko, M., et al. (2015) Concussion Under-Reporting and Pressure from Coaches, Teammates, Fans, and Parents. Social Science \& Medicine, 134, 66-75. https://doi.org/10.1016/j.socscimed.2015.04.011

[88] Kroshus, E. and Baugh, C.M. (2016) Concussion Education in U.S. Collegiate Sport: What Is Happening and What Do Athletes Want? Health Education \& Behavior, 43, 182-190. https://doi.org/10.1177/1090198115599380 